\title{
PERSPECTIVAS DEL DERECHO COOPERATIVO
}

\author{
Dante Cracogna \\ Universidad de Buenos Aires
}

\section{RESUMEN}

El artículo versa sobre la construcción del Derecho Cooperativo y para ello plantea las razones que justifican su existencia sobre la base de un enfoque fundado en el análisis de la experiencia cooperativa. Comienza ocupándose de los orígenes y el desarrollo de la legislación cooperativa que surgió como consecuencia de la necesidad de regular un fenómeno social novedoso y la influencia que sobre ella ejercieron los principios cooperativos declarados por la Alianza Cooperativa Internacional. Señala los rasgos propios que caracterizan a las cooperativas y que provocaron una paulatina autonomía de la legislación cooperativa con relación a las legislaciones en las que se encontraba incorporada. A partir de la autonomía legislativa señala la necesidad de una aproximación científica que, junto con una adecuada autonomía didáctica, construya las bases del Derecho Cooperativo capaz de hacerse cargo de su objeto propio y diferenciado. Concluye analizando los riesgos que amenazan la existencia del Derecho Cooperativo y considera los condicionamientos que imponen las estructuras políticas territoriales como así también los mecanismos para su superación.

PALABRAS CLAVE: Derecho cooperativo, legislación cooperativa, ciencia jurídica, acto cooperativo, principios cooperativos.

CLAVES ECONLIT / ECONLIT DESCRIPTORS: P13, K220, A13, L30, L31.

Cómo citar este artículo/How to cite this article: CRACOGNA, D.: "Perspectivas del Derecho Cooperativo", CIRIEC-España, Revista Jurídica de Economía Social y Cooperativa, n 39, 2021, pp. 13-44. DOI: 10.7203/CIRIEC-JUR.39.21824 


\section{PERSPECTIVES OF COOPERATIVE LAW}

\section{EXPANDED ABSTRACT}

The article deals about the building up of the Cooperative Law taking into account the reasons for its existence -based on the analysis of the cooperative experience. It starts considering the meaning of Law and legislation and making clear the difference between both concepts in as much as the former is wider comprising legislation as well as the sentences of the courts and the doctrine of the authors. Within this framework it goes into the origins of the cooperative legislation which arose from the need to regulate a new social phenomena -the cooperative- which obviously had no regulation at the time of its inception to the point that the first cooperative had to register under the act regulating the friendly societies. Cooperative acts started to be enacted in the second half of the XIX Century and later developed in three main trends: autonomous in Europe and North America; promotional in India and other colonial countries and State controlled in the USSR and its satellites countries. Changes in the developing countries and the implosion of the Soviet Union together with the proclamation of autonomy and independence as a cooperative principle were reducing the last two legislative models and today the first one is predominant worldwide.

The influence exerted by the Cooperative Principles laid down by the International Cooperative Alliance at its Paris Congress of 1937 and reformulated in 1966 determined that cooperative legislation started to adopt a peculiar profile different from that of commercial companies and other types of organizations. The Statement on the Cooperative Identity approved by the ICA at its Centennial Congress held in Manchester in 1995 is the last and most complete doctrinal document containing the definition of a cooperative, the cooperative values and the cooperative principles. This statement is actually exerting a notable influence on cooperative legislation worldwide during the last decades backed by its recognition in international documents such as the Resolution of the UN Assembly 56/117 (Annex: Guidelines aiming at creating a supportive environment for the development of cooperatives) and OIT Recommendation 193 on the Promotion of Cooperatives.

The article points out that the specific characters of the cooperatives caused a progressive independence of the cooperative legislation from the legislations where it used to be incorporated, such as the Civil or Commercial Codes or other Law bodies. In such a way the cooperative legislation commenced to gain a proper space and recognition as being distinct because it regulates a peculiar organization. It can be said that the legislative autonomy is the first step in building the Cooperative Law; however, being it an important step it is only the first one and in many countries is still not complete due to the fact the cooperative iden- 
tity is not yet entirely recognized as different from that of the capital enterprises. The author emphasizes that the clue in this question is to find the specific object that characterizes the cooperative and justifies it to be treated as a different subject. It appears that the fact that members of the cooperative are at the same time the owners and the users of the cooperative gives to it a special character consistent with the circumstance that the cooperative is at the same time an association of persons and an economic enterprise. Consequently, this peculiar relation between the cooperative and its members become the peculiar feature that makes the cooperative different from capital societies and associations and a specific legal theory can and should be constructed upon it.

The specificity of the cooperative legislation painfully obtained after years of efforts done in order to get recognition of the difference among cooperatives and other forms of enterprises is being permanently and increasingly threatened by a tendency to treat all enterprises in the same fashion ("one measure fits all"). The argument used is that equal treatment ensures fair competence ignoring that equal treatment is just only among equals and that cooperatives are different; the question is not to render the cooperatives preferences or privileges but a treatment according to its specific nature. In this respect, the legislative autonomy of the cooperatives needs to be protected by a rigorous scientific approach by the scholars providing sound basis to the legislators and the judges for a clear view and comprehension of this subject. The Academy has an important role to play in the advancement of the Cooperative Law going beyond the mere cooperative legislation but, unfortunately, up to the moment not enough has been done in this filed specially in teaching and researching at the Law schools. Nevertheless, it has to be stated that in several countries Cooperative Law is being taught as a separated subject thus gaining teaching autonomy and valuable publications about the matter have been done. Even more, comparative studies on Cooperative Law are starting to appear considerably enlarging the horizons for the advancement of the subject.

At the same time, threatens arise from other fields of the Law risking the autonomy of the Cooperative Law: besides what has been said about Corporate Law, Labor Law claims that worker cooperatives are part of it; Administrative Law pretend that public utilities cooperatives are to be regulated only by it; Consumer Law affirms that consumer cooperatives are subjected to it; Competence Law and Tax Law have similar approaches; and so on. The challenges are numerous and among them there are some that are not so frontal but more subtle. Such is the case of the CRS which tries to demonstrate that the social aspects of the cooperatives are well -or even better- performed by capital enterprises. Besides, very often social economy enterprises (or solidarity ones or popular ones) also aspire to demonstrate that cooperatives have no difference with them and aim at confining cooperatives only as a mere example of Social Economy. 
Another front of trouble for Cooperative Law is presented by the political organization of countries where the legislative competences are split in different jurisdictions: federal state and provinces or nation and regions. In those cases conflicts or differences may arise which can undermine the unity and consistence of Cooperative Law even in one single country. Similar situation might appear within spaces of economic and political integration where norms originated in the different countries coexist with those enacted by the supranational authorities. Of course in these cases harmonization is necessary in order to avoid problems for cooperatives and ensuring the existence and progress of Cooperative Law as a single unit; here again law experts and academics have an important role to play.

KEYWORDS: Cooperative law, cooperative legislation, legal science, cooperative act, cooperative principles. 


\section{SUMARIO}

I. Legislación y derecho. II. Orígenes y desarrollo de la legislación cooperativa. III. La constitución del Derecho Cooperativo. IV. Los esfuerzos de personalización del Derecho Cooperativo. V. El objeto propio. VI. Aproximaciones que amenazan la singularidad del Derecho Cooperativo. VII. La geografía del Derecho Cooperativo. Bibliografía

\section{Legislación y derecho}

Si el derecho es la regulación de la vida humana en sociedad ${ }^{1}$, su primera expresión es la costumbre como comportamiento reiterado frente a las circunstancias similares que se presentan en la vida social y que permite orientar las conductas individuales afianzando la convivencia y el entendimiento comunitario. Empero, desde los albores de la civilización la costumbre fue seguida por la legislación como medio de dar mayor certeza y firmeza a las normas consuetudinarias ${ }^{2}$ y la importancia de ella ha ido creciendo de manera sostenida hasta hacerse preponderante, de tal suerte que la ley escrita alcanzó hegemonía en el mundo moderno. Cuando se afianza el constitucionalismo como expresión jurídico filosófica del nuevo orden político, la supremacía del legislador entendido como manifestación de la voluntad del pueblo representada en el parlamento, la ley adquiere absoluta supremacía sobre toda otra regulación de conducta ${ }^{3}$. De ella derivan las otras manifestaciones normativas -legislación en sentido material- tales como los decretos, las reglamentaciones, resoluciones y demás formas de regulación de los comportamientos.

En suma, en la actualidad la ley es la manifestación por excelencia del derecho, pero el derecho no se agota en la ley, ni siquiera en la ley en sentido amplio, material. El derecho tiene un significado de mayor alcance. En efecto, además de contener las reminiscencias consuetudinarias que en algunos casos alcanzan relativa importancia, también comprende a las decisiones de los tribunales que constituyen asimismo re-

1. Ubi homo ibi societas ubi societas ibi ius es el adagio latino que mejor refleja la naturaleza de derecho como una manifestación necesaria de la vida en comunidad, producto de la propia naturaleza social del hombre.

2. El Código de Hammurabi y las Leyes de las doce tablas son ejemplos paradigmáticos.

3. Vid. KRYGIER, M.: "Rule of Law". En: The Oxford Handbook of Comparative Constitutional Law (eds. ROSENFELD, M. \& SAJÓ, A.), Oxford University Press, Oxford, 2012, p. 233-234. 
levantes manifestaciones normativas, aunque de alcance particular a diferencia de la legislación cuyo carácter general constituye nota característica ${ }^{4}$.

A la legislación y la jurisprudencia -entendida esta última en el sentido de los pronunciamientos de los tribunales ${ }^{5}$ ha de agregarse en la época contemporánea la doctrina de los autores o jurisconsultos como parte integrante del derecho aún cuando no contenga un sentido específicamente normativo ${ }^{6}$. Este bagaje teórico de los eruditos constituye también parte relevante del derecho en tanto coadyuva a interpretar y precisar el significado y los alcances tanto de la legislación como de la jurisprudencia a la vez que constituye un elemento que influencia decididamente en la elaboración de ambas. Por otro lado, la doctrina es también la reflexión teórica que contribuye a perfilar el carácter científico de los estudios jurídicos referidos a la materia, superando la mera tarea expositiva y descriptiva de normas, elevándose a un nivel epistemológico superior ${ }^{7}$.

De lo dicho se desprende que legislación y derecho son claramente diferentes, aun cuando este último comprende a la primera. De manera que no podría existir derecho sin legislación, pero, en cambio, puede ciertamente existir legislación sin que haya derecho, sea porque no hay reflexión teórica acerca de aquélla o porque sea ésta de nivel insuficiente. Asimismo, el derecho puede comprender la totalidad del ordenamiento jurídico, en cuyo caso se convierte en una teoría general o bien abarcar sólo una parte o rama, deviniendo entonces en un derecho particular o especial. O bien puede abarcar una nación o región o extenderse al ámbito internacional. Asimismo, podría referirse a un determinado período histórico o al momento actual. Todas esas variantes dan origen a campos o provincias del amplio y diversificado conocimiento jurídico de nuestros días y constituyen el telón de fondo sobre el que se proyectan las reflexiones sobre el tema de este trabajo.

4. Kelsen ha enfatizado y demostrado con rigor que las resoluciones emanadas de los órganos jurisdiccionales revisten carácter normativo con iguales títulos que las leyes, si bien con alcance individual. Vale decir que tanto unas como otros (leyes y pronunciamientos judiciales) tienen una misma naturaleza normativa en el sentido de regulación de conductas (KELSEN, H.: Teoría Pura del Derecho, Universidad Nacional Autónoma de México (UNAM), México D. F., 1979, p. 248).

5. Vale la aclaración del texto toda vez que en el mundo anglosajón la palabra jurisprudence suele ser entendida con el sentido de ciencia jurídica o, incluso, de teoría general del derecho.

6. Distinta era la situación en Roma en la época del Imperio en la que los jurisconsultos -al menos algunos de ellos- eran autorizados a expedirse ex auctoritate principii y no solamente ex propria et privata auctoritate como en la época clásica (CUETO RÚA, J.: Fuentes del derecho, Editorial Abeledo-Perrot, Buenos Aires, 1994, p. 186).

7. La constitución de la ciencia jurídica en cuanto tal es un producto relativamente reciente en la historia del pensamiento, pese a que la existencia de la legislación es muy antigua. 
Cabe notar que las precisiones que anteceden resultan necesarias toda vez que se suele utilizar con frecuencia la expresión Derecho Cooperativo sin advertir claramente su significado específico, tal vez por mera comodidad de lenguaje o descuido puesto que, en rigor, se hace referencia a la legislación cooperativa.

\section{Orígenes y desarrollo de la legislación cooperativa}

Es sabido que la primer cooperativa del mundo reconocida como tal -Rochdale Society of Equitable Pioneers ${ }^{8}$ - hubo de inscribirse en el registro de las friendly societies regidas por la ley de 1796. Estas eran las asociaciones mutuales de la época y la inscripción en el registro de ellas obedeció a que eran las entidades que mayor semejanza guardaban con la Cooperativa de Rochdale cuyo reconocimiento legal se estimaba requisito necesario para habilitar su funcionamiento regular'.

La carencia de una regulación legal específica se explica por cuanto las notas caracterizantes de la Cooperativa de Rochdale resultaban originales; y al no ser susceptibles de encuadrar en ninguno los tipos asociativos o societarios a la sazón existentes quedaban por fuera de ellos. En suma, no había ley ni registro que contuvieran específicamente a esta novedosa forma de organización ${ }^{10}$. Y a medida que numerosas organizaciones similares iban surgiendo, esta carencia legal provocó la necesidad de contar con un régimen propio que diera cuenta de la novedosa experiencia que había surgido y se desarrollaba con notable ímpetu.

8. Debe señalarse que, en la Inglaterra de esa época, especialmente en la región del Norte donde la Revolución Industrial había tenido sus comienzos y en la cual se situaba la Cooperativa de Rochdale, se produjeron numerosas experiencias similares que tuvieron corta vida. De manera que hablar de la Cooperativa de Rochdale como la primera exige la precisión de señalar que se trata de la primera en alcanzar éxito y permanencia. De allí la notable influencia que ejerció en el posterior desarrollo del movimiento cooperativo puesto que se convirtió en el modelo a seguir merced a la difusión de su estatuto que contenía las reglas que explican su perdurabilidad y que, con el tiempo, se habrían de convertir en los principios cooperativos universalmente reconocidos. La historia de los pioneros, magistralmente relatada por su contemporáneo Georges Jacob Holyoake, alcanzó difusión universal. Existe una versión reducida en espańol traducida por Bernardo Delom y publicada por la Federación Argentina de Cooperativas de Consumo en el ańo del centenario de la Cooperativa Rochdale, luego reproducida varias veces por Intercoop, Buenos Aires, hasta 2016.

9. La Friendly Societies Act de 1783 tuvo importantes reformas en 1834 que permitieron a las primeras cooperativas registrarse conforme con sus previsiones como mutual trading societies (SOUTHERN, R. \& ROSE, P.B.: Handbook to the Industrial and Provident Societies Act 1893-1961, Co-operative Union Ltd., Manchester, 1961, pp. 13-14).

10. Se ha señalado "the disabilities under which the Co-operative Movement suffered in its early days in the absence of any assured legal foundation for its existence." (COLE, G.D.H.: A Century of Co-operation, George Allen and Unwin Ltd. for The Co-operative Union Ltd., Stockport, 1944, p. 114). 
Los socialcristianos miembros del Parlamento fueron quienes asumieron la tarea de promover dicho régimen, el cual fue finalmente adoptado mediante la Industrial and Provident Societies Act de $1852^{11}$. Curiosamente, la nueva ley no mencionaba la palabra cooperativa, la que solamente fue acogida por la legislación británica un siglo y medio más tarde. Puede afirmarse que el adagio romano jus oritur facto se cumplió acabadamente pues la experiencia cooperativa nació y se desarrolló antes de que el legislador se hiciera cargo de esta nueva realidad y le definiera su marco normativo propio $^{12}$.

A partir de entonces fueron apareciendo leyes de cooperativas en diferentes países en los que ya existían estas entidades, Así, en 1867 se sancionó la ley prusiana, fruto en gran medida de la acción parlamentaria de Herman Schultize-Delitsh que había desarrollado una intensa actividad de promoción de las cooperativas urbanas de crédito en Alemania ${ }^{13}$. En el mismo año tuvo lugar las promulgación de la ley francesa de sociedades que incluyó un capítulo sobre las sociedades de capital variable, comprensivo de las cooperativas ${ }^{14}$. De tal suerte, quedaban iniciadas las tres grandes líneas europeas de legislación cooperativa cuya influencia se iría prolongando a lo largo del tiempo en diferentes países. Paralelamente, algunos estados americanos fueron también sancionando leyes de cooperativas: Michigan en primer lugar en 1865, al que siguieron Wisconsin y otros ${ }^{15}$, al igual que varias provincias en Canadá, comenzando por Ontario, cuya ley se basó en la Industrial and Provident Societies Act inglesa ${ }^{16}$.

11. Arnold Bonner, afirma: "The formation and development of co-operative societies were hindered by the lack of suitable legislation, and this the Christian Socialists were quick to realize." (BONNER, A.: British Cooperation, Co-operative Union, Manchester, 1961, p. 66).

12. El primer registrador de cooperativas fue John M. F. Ludlow, quien había tenido importante intervención en la sanción del nuevo régimen legal. Esa circunstancia favoreció el proceso de reconocimiento legal de las numerosas cooperativas que ya existían a esa altura (VALKO, L.: "The First Co-operative Law", Review of International Co-operation, Alianza Cooperativa Internacional (ACI), London, 1952).

13. La ley prusiana de 1867 fue adoptada por el Imperio Alemán en 1871 y tuvo importantes modificaciones en 1889. Esta ley, con la reforma de 1898, rigió prácticamente sin modificaciones hasta 1973 (MÜNKNER, H.H.: "Nueva ley cooperativa de 1973 y evolución de la legislación cooperativa en la República Federal de Alemania”, Organización Internacional del Trabajo (OIT), Ginebra, 1973, pp. 49-50).

14. Lucien Coutant, en su reconocida obra histórica L'evolution du droit coopératif de ses origines à 1950 (1950), explica los motivos por los que, en lugar de dictarse una ley específica sobre cooperativas, se incluyó su regulación dentro de la ley de sociedades.

15. Vid. VALKO, L.: Cooperative Laws in the U.S.A. Federal Legislation 1890-1980, Washington State University, College of Agriculture, 1981.

16. Vid. PETROU, T.: "Canada”. En: International Handbook of Cooperative Law (eds. CRACOGNA, D., FICI, A. \& HENRŸ, H.), Springer, Heidelberg, 2013, p. 290. 
A pesar de sus singularidades locales, todos los casos mencionados tuvieron un patrón de origen semejante, es decir las legislaciones se fundaron en la experiencia ${ }^{17}$. Pero en los primeros años del Siglo XX apareció un modelo diferente de legislación cooperativa: la legislación dictada para promover la creación de cooperativas. En este caso, a diferencia del anterior modelo ya difundido en Europa y América del Norte, la legislación era previa a la existencia de cooperativas; su objetivo consistía, precisamente, en fomentar su establecimiento ${ }^{18}$. Así surgió la legislación cooperativa de la India en 1904, modelo que -con variantes- fue posteriormente aplicado en otros países coloniales -no solamente británicos- y también en países independientes de diferentes regiones del mundo en desarrollo ${ }^{19}$.

Por otra parte, el advenimiento del socialismo en la ex Unión Soviética y sus naciones satélites produjo un singular modelo de legislación en el que las cooperativas quedaban incluidas dentro del aparato de la economía estatal y, por ende, sujetas a las directivas de la planificación centralizada. Este modelo mantuvo vigencia hasta la caída del muro de Berlín y posterior transformación tanto de la Unión Soviética como de los demás países del antiguo COMECON ${ }^{20}$.

En consecuencia, en el Siglo XX tres modelos de legislación cooperativa estuvieron vigentes en el orden mundial, a saber: el autónomo, el promocional y el planificado. Sin embargo, el último prácticamente desapareció con la implosión del llamado socialismo real ${ }^{21}$, en tanto que el segundo ha ido atenuando su vigencia por el proceso de

17. Cabe recordar que a nivel internacional la ACI demostró un temprano interés por la legislación cooperativa, como lo evidencia el hecho de haber tratado el tema en Congreso de Delft en 1897 (WATKINS, W.P.: La Alianza Cooperativa Internacional 1895-1970, Intercoop Editora Cooperativa, Buenos Aires, 1973, p. 87). Ese interés se ha acentuado en los años recientes, como lo demuestran la creación de un Comité de Derecho Cooperativo, replicado en cada una de las regiones que constituyen la ACI, y la inclusión de un capítulo especial sobre marcos jurídicos en el Plan para una década cooperativa aprobado por la ACI en 2012, proclamado "Año Internacional de las Cooperativas" por la ONU.

18. Vid. MÜNKNER, H.H. (ed.): 100 Years Co-operative Credit Societies Act India 1904, Marburg Consult for Self-help Promotion, Marburg, 2005. Claramente, el gobierno colonial británico que promovió esta legislación trataba de impulsar el desarrollo de la India, principalmente en el medio rural, para lo cual realizó estudios de la experiencia cooperativa en países europeos y luego adoptó una legislación de fomento cooperativo que consideró apropiada a tales fines.

19. Sobre la experiencia en las colonias británicas de Asia y Africa es ilustrativa la exposición de: CAMPBELL, W.K.H.: Practical Co-operation in Asia and Africa, W. Heffer, Cambridge, 1951; CALVERT, H.: The Law and Principles of Co-operation, Thacker, Spink \& Co., Calcutta, 1933; y SURRIDGE, D.J. \& DIGBY, M.: A Manual of Co-operative Law and Practice, W. Heffer, Cambridge, 1958.

20. Durante un tiempo, el antiguo modelo de la planificación estatal de Rusia y sus países satélites pasó a llamarse "de transición" hasta su paulatina desaparición.

21. No obstante, cabe advertir que existen casos de países, como China y Cuba, en los cuales todavía subsisten resabios del antiguo modelo de subordinación estatal. 
descolonización y la paulatina afirmación de autonomía e independencia de las cooperativas principalmente por virtud de la evolución de los principios cooperativos ${ }^{22}$.

Por lo tanto, progresivamente las legislaciones de cooperativas han ido convergiendo, si bien con variantes, hacia un modelo único basado en el reconocimiento de los rasgos propios de estas entidades con énfasis en su autonomía respecto del Estado.

\section{La constitución del Derecho Cooperativo}

La constitución del Derecho Cooperativo supone la existencia de una legislación específica que le brinde sustento y motivo a su existencia; no podría existir un Derecho Cooperativo que no se asentara sobre la base de una legislación propia puesto que se trataría de una mera construcción teórica. Todo derecho se entiende como el estudio de las normas que rigen la convivencia social ${ }^{23}$; por lo tanto, si tales normas no existen, tampoco puede concebirse el derecho.

Hacia mediados del Siglo XX ya existía legislación sobre cooperativas en buena parte de los países del mundo, cubriendo los distintos continentes. Más allá de la diversidad de manifestaciones y formas de dichas legislaciones puede afirmarse sin hesitación que ellas se referían a un mismo objeto; vale decir que tenían una sustancial identidad de contenido. El fundamento de dicha identidad se encontraba -básicamente- radicada en los llamados principios cooperativos que fueron proclamados por la Alianza Cooperativa Internacional (ACI) ${ }^{24}$. Tales principios fueron discernidos a partir de los estatutos de la Cooperativa de Rochdale y formalmente declarados, después de varios años de estudio y consultas, por el Congreso de la ACI realizado en París en $1937^{25}$. Esta declaración significó un espaldarazo decisivo para afirmar

22. Es notable cómo la enunciación de los principios cooperativos fue evolucionada hacia el reconocimiento pleno de la autonomía e independencia de las cooperativas, claramente plasmado en el $4^{\circ}$ principio de la Declaración sobre la Identidad Cooperativa aprobada por el Congreso del Centenario de la Alianza Cooperativa Internacional realizado en Manchester en 1995, pocos años después de la caída de los regímenes comunistas de Europa.

23. Si bien hay diferentes nociones de derecho, como se recordó antes, existe consenso general acerca de que éste consiste en la regulación de conductas, expresada mediante las normas jurídicas, de las que la legislación es la más relevante.

24. La ACI fue fundada en Londres en 1895 y es una de las más antiguas organizaciones no gubernamentales de nivel internacional existentes en el mundo. Tiene actualmente su sede en Bruselas y cuenta con organizaciones afiliadas en más de 120 países. La ONU le ha reconocido status consultivo A en el Consejo Económico y Social. 
los caracteres peculiares definitorios de la personalidad de las cooperativas, los cuales fueron siendo paulatinamente incorporados en las legislaciones de la materia.

Los principios cooperativos fueron objeto de una reformulación en el Congreso de la ACI realizado en Viena en 1966, la cual no alteró su esencia pero sirvió para precisar algunos rasgos de las cooperativas a la luz de las nuevas circunstancias económicas y sociales del mundo ${ }^{26}$. De igual manera sucedió en 1995 como resultado del Congreso realizado en Manchester con el que la ACI celebró el centenario de fundación ${ }^{27}$. Puede afirmarse que de manera paulatina la difusión y reconocimiento de los principios cooperativos de la ACI ha ido creciendo sostenidamente, siendo la Declaración de la Identidad Cooperativa aprobada en el Congreso de Manchester un documento que alcanzó una repercusión e influencia que no habían tenido las anteriores formulaciones ${ }^{28}$.

Lo cierto es que a lo largo del tiempo la ACI fue consolidando su papel de depositario y custodio de los principios cooperativos ${ }^{29}$, circunstancia que dio lugar a que se fuera reforzando el carácter universal de éstos de manera indiscutida. Ello sucede no solamente con las cooperativas de prácticamente todas las actividades y todos los países sino también con los organismos internacionales que fueron reconociendo de manera generalizada la personalidad y representatividad de la ACI y, correlativamente, de los principios por ella proclamados ${ }^{30}$. Esto último quedó palmariamente

26. Vid. ALIANZA COOPERATIVA INTERNACIONAL [ACI]: Twenty-Third Congress. Agenda and Reports. 5th to 8th September, 1996, Alianza Cooperativa Internacional (ACI), Bruselas, 1996, pp. 49 y ss. El informe de la comisión, escrito por su relator W. P. Watkins, es particularmente ilustrativo acerca del sentido y el alcance de las reformas introducidas y de la experiencia recogida a lo largo de la vigencia de la anterior declaración.

27. Vid. MACPHERSON, I.: Cooperative Principles for the 21st Century, Alianza Cooperativa Internacional (ACI), Ginebra, 1995. Esta publicación contiene, además de la Declaración sobre la Identidad Cooperativa, dos importantes artículos del autor que ilustran acerca del sentido del documento. Asimismo, resulta ilustrativo: ALIANZA COOPERATIVA INTERNACIONAL [ACI]: Guidance Notes to the Co-operative Principles, Alianza Cooperativa Internacional (ACI), Brussels, 2015; documento elaborado por una comisión especial designada por la ACI y publicado 20 años después de la Declaración.

28. Sobre la recepción de los principios cooperativos en la legislación cooperativa europea es destacable, vid. FAJARDO GARCÍA, I.G., FICI, A., HENRŸ, H., HIEZ D., MÜNKNER, H.H. \& SNAITH, I.: "El nuevo grupo de estudio en derecho cooperativo europeo y el proyecto 'Los principios del derecho cooperativo europeo", CIRIEC-España, Revista Jurídica de Economía Social y Cooperativa, n² 24, 2013, pp. 331 y ss.

29. No obstante, otras organizaciones internacionales que nuclean a ciertas clases de cooperativas también formularon principios, tal como sucedió con la International Raiffeisen Union (IRU) para las cooperativas agrarias y el World Council of Credit Unions (WOCCU) para las cooperativas de ahorro y crédito.

30. Cabe recordar que el primer Director de la OIT, Alberto Thomas, era un importante dirigente cooperativista que había formado parte del consejo de la ACI y creó el Servicio de Cooperativas del Organismo que continúa hasta el presente desarrollando una proficua labora de estudio y promoción de las cooperativas y, 
demostrado con Resolución 56/114 de la Asamblea General de las Naciones Unidas que en 2001 se refirió expresamente a los principios contenidos en la Declaración sobre la Identidad Cooperativa ${ }^{31}$ y la Recomendación $N^{\circ} 193$ de la OIT sobre promoción de las cooperativas que contiene como anexo la mencionada Declaración ${ }^{32}$. El reconocimiento de los principios cooperativos por parte de los organismos internacionales, como asimismo el trabajo conjunto de éstos con la ACI, ha cumplido un importante papel conducente a plasmar dichos principios en las legislaciones de numerosos países ${ }^{33}$.

Como conclusión de lo dicho puede afirmarse que se ha cumplido la tradicional situación en la que los hechos preceden y condicionan a la legislación, y por ende al derecho, puesto que la experiencia cooperativa traducida en los principios que la informan precedió a la legislación que la reguló posteriormente.

Por otra parte, desde mediados del Siglo XX comenzaron a realizarse estudios comparativos de la legislación cooperativa en distintas regiones del mundo que contribuyeron a ilustrar acerca de los avances que se iban produciendo y las experiencias realizadas. De esa forma también se fue produciendo un significativo avance teórico en la materia y un positivo intercambio entre investigadores y estudiosos. Estos estudios fueron progresando desde enfoques limitadamente regionales o sectoriales hacia una cobertura geográfica cada vez más amplia y de mayor rigor técnico ${ }^{34}$.

particularmente, de la legislación cooperativa en numerosos países. Destacados autores en materia cooperativa fueron jefes del mencionado Servicio, entre los que cabe mencionar a Georges Fauquet y Hagen Henrÿ. Por su parte, como se recordó, la ONU confirió a la ACI status consultivo clase A en su Consejo Económico y Social en 1946.

31. La Resolución 56/114, adoptada por la Asamblea General en 2001, contiene unas "Directrices orientadas a crear un ambiente propicio para el desarrollo de las cooperativas" cuyo párrafo 11 al referirse a la legislación cooperativa señala que debe estar conforme con la Declaración sobre la ldentidad Cooperativa de la ACI.

32. La Recomendación $\mathrm{N}^{\circ} 193$ aprobada por la Conferencia General de la OIT expresamente determina en el párrafo 10 que los Estados miembros deben adoptar una legislación sobre cooperativas fundada en los valores y principios establecidos por la ACI en la Declaración sobre la Identidad Cooperativa.

33. Es oportuno mencionar que el 22 de julio de 2021 se difundió el Informe del Secretario General de la ONU titulado "Cooperatives in social development" (A/76/209) cuyo extenso capítulo III está dedicado al marco legal y regulatorio y enfatiza las "special characteristics of cooperatives and the need for cooperative law."

34. Los primeros estudios estuvieron circunscriptos principalmente a países europeos o a regiones coloniales homogéneas, tales como: DIGBY, M.: Digest of Co-operative Law at Home and Abroad, The Horace Plunkett Foundation, London, 1933; VALKO, L.: International Handbook of Co-operative Legislation, State College of Washington, Pullman, 1954; CHÁVEZ NUNEEZ, F. \& ORIZET, J.: Estudio comparativo de la legislación cooperativa en América, Organización de los Estados Americanos (OEA), Washington, 1957; CONFEDERACIÓN EUROPEA DE LA AGRICULTURA [COGECA]: Estudio comparado del derecho de la cooperación agrícola en Europa, Obra Sindical "Cooperación”, Madrid, 1965. Posteriormente cabe mencionar los estudios 
Sin embargo, no sólo la legislación constituye el derecho. Este es un fenómeno más complejo en el que incide también la actividad de los órganos judiciales encargados de precisar su alcance mediante la interpretación y aplicación de ella ${ }^{35}$. La legislación produce las normas de carácter general pero los jueces tienen la tarea de su interpretación y aplicación en los casos concretos sometidos a su decisión y lo hacen mediante el dictado de las sentencias que constituyen las normas individuales. De suerte tal que dichas normas, constitutivas del conjunto denominado jurisprudencia, vienen a formar parte del derecho conjuntamente con las normas generales ya que de otra manera éstas quedarían en meras declaraciones sin eficacia práctica en la vida social. La jurisprudencia en materia de cooperativas es, pues, un componente fundamental del Derecho Cooperativo ${ }^{36}$. De allí que el conocimiento de la legislación cooperativa de un determinado país no sea por sí solo suficiente para conocer el Derecho Cooperativo de ese lugar puesto que le falta el ingrediente fundamental de su traducción en la realidad social mediante la acción de los tribunales.

Aun más, como antes se dijo, la doctrina desempeńa un papel relevante para analizar e interpretar las normas generales y particulares relativas a la materia cooperativa y para edificar la construcción teórica que les brinde estructura sistemática, más allá de la mera acumulación de información acerca de ellas. Por lo tanto, es la doctrina como expresión de la ciencia jurídica la que construye el Derecho Cooperativo con

de Africa: MÜNKNER, H.H. \& ULLRICH, G. (eds.): Cooperative Law in East, Central and Southern African countries, German Foundation for International Development, Berlin, 1982; y en época más reciente: MONTOLIO HERNÁNDEZ, J.M.: Legislación cooperativa en América Latina. Situación, derecho comparado y proceso de armonización, Ministerio de Trabajo y Seguridad Social, Madrid, 1990; e ibid.: Legislación cooperativa en la Unión Europea, Ministerio de Trabajo y Asuntos Sociales, Madrid, 2001; CRACOGNA, D. (coord.): Régimen legal de las cooperativas en los paises del Mercosur, Instituto Nacional de Asociativismo y Economía Social (INAES), Buenos Aires, 2009; ibid.: La legislación cooperativa en los países andinos Alianza Cooperativa Internacional para las Américas (ACI-Américas), San José, 2009; e ibid.: La legislación cooperativa en México, Centroamérica y el Caribe, Alianza Cooperativa Internacional para las Américas (ACI-Américas), San José, 2009. Por fin, el estudio más abarcativo a escala global: CRACOGNA, D., FICI, A. \& HENRŸ, H. (eds.): International Handbook of Cooperative Law, Springer, Heidelberg, 2013; que, además de estudios generales, contiene capítulos referidos a más de treinta países de todas las regiones del planeta. Corresponde asimismo mencionar los estudios de marcos legales cooperativos realizados en virtud del acuerdo celebrado entre la ACI y la Unión Europea que promovió un relevamiento de la legislación cooperativa de más de noventa países de las cuatro regiones que conforman la ACI, a saber: Africa, Américas, Asia-Pacífico y Europa, a cargo de expertos de cada uno de los países y con una síntesis de cada región. (Se puede consultar en coops4dev).

35. Con razón se ha afirmado que la ley dice lo que los jueces dicen que ella dice.

36. La sección de jurisprudencia de la revista CIRIEC-España, Revista Jurídica de Economía Pública, Social y Cooperativa es una muestra cabalmente representativa de la importancia que los pronunciamientos judiciales, especialmente de los tribunales superiores, reviste para el Derecho Cooperativo. 
base en la reflexión teórica sobre las normas jurídicas que lo integran ${ }^{37}$. Esta tarea supone una acción conjunta de estudiosos y autores que tematizan específicamente esta materia, tarea de investigación que normalmente se realiza en el ámbito universitario donde también se transmite ese conocimiento a través de la docencia ${ }^{38}$.

\section{Los esfuerzos de personalización del Derecho Cooperativo}

La historia del Derecho Cooperativo se resume en un titánico y permanente esfuerzo por lograr su personalización, desprendiéndose de otras ramas del derecho ${ }^{39}$. Ello sucedió cuando el régimen legal de las cooperativas se encontraba contenido en algún código determinado (comercial, civil, del trabajo, etc.) puesto que dicha inclusión se consideraba como una afirmación de pertenencia a la rama del derecho en cuestión y con ese argumento se pretendía clausurar todo intento de reconocimiento singular. Sin embargo, aun cuando se dictaron leyes especiales sobre cooperativas se siguió sosteniendo que ellas formaban parte de alguna de las tradicionales ramas del derecho, especialmente el comercial ${ }^{40}$.

Sucede que, históricamente, el régimen jurídico de las cooperativas anidó en algunas de las ramas del derecho existentes al momento de su aparición, según los distintos países, y allí se desarrolló, tal como fue explicado anteriormente ${ }^{41}$. Sin em-

37. Vid. ZULETA PUCEIRO, E.: "La dogmática jurídica como paradigma científico", Anuario de Filosofía Jurídica y Social, no 3, 1983, p. 395.

38. Henrÿ señala que actualmente la academia está mostrando un renovado interés en la materia (vid. HENRŸ, H.: "Trends and Prospects of Cooperative Law". En: International Handbook of Cooperative Law (eds. CRACOGNA, D., FICI, A. \& HENRŸ, H.), Springer, Heidelberg, 2013, p. 804).

39. Vid. HENRŸ, H.: Guidelines for Cooperative Legislation, Organización Internacional del Trabajo (OIT), Ginebra, 2012, pp. 9-10.

40. Así, por ejemplo, Carlos Vargas Vasserot, puntualiza que las cooperativas forman parte de las sociedades comerciales, es decir que integran el derecho comercial (vid. VARGAS VASSEROT, C.: "La teoría del acto cooperativo en el derecho español". En: Congreso Continental de Derecho Cooperativo. San José de Costa Rica, 18-20 de noviembre de 2019 (comp. CRACOGNA, D.), Intercoop Cooperativa Editoria, Buenos Aires, 2020, pp. 36-37).

41. En los países de la UE, donde el Tratado de Roma incluye a las cooperativas entre las sociedades, se ha dado por sentado -en la mayoría de ellos- que las cooperativas son sólo una especie del género de las sociedades comerciales. Por lo tanto, aunque existe doctrina de relevante nivel teórico acerca de las cooperativas, ésta solamente alcanzó una dimensión modesta que le privó de acceder al nivel de la constitución de una rama jurídica autónoma. toda vez que sus presupuestos se hallaban anclados en la teoría de las sociedades comerciales. Es ilustrativa la afirmación de Enrique Gadea Soler: "Dicho con toda claridad, no vemos ninguna dificultad para 
bargo, ello no es razón suficiente para que permanezca necesariamente recluido en ese ámbito puesto que puede alcanzar la mayoría de edad y ganar su identidad propia como aconteció con otras ramas que, nacidas de un mismo tronco, fueron logrando progresivamente su personalidad singular como para convertirse en autónomas. Si ello no fuera posible, el derecho en general estaría condenado a una quietud permanente que lo anquilosaría, privándolo de la fuerza dinámica que el progreso social inevitablemente conlleva ${ }^{42}$. Y en ese empeño, la legislación cumple un papel relevante toda vez que constituye la fuente más dinámica del derecho moderno que suele operar con mayor celeridad -y predicamento- que las restantes. Una vez que la legislación da el primer paso, las demás fuentes suelen seguirla. Así sucede con la legislación cooperativa. Pero para que se justifique la autonomía no solamente tiene que existir la legislación especial puesto que formas jurídicas diferentes hay muchas que no constituyen ramas especiales; por ejemplo, sociedades comerciales anónimas, colectivas, en comandita, etc. pero todas ellas están cobijadas bajo el género de las sociedades comerciales del que sólo constituyen especies que no varían lo sustancial de su naturaleza. Y es aquí donde las cooperativas destacan con una singularidad que excede el marco de aquéllas pues tienen notas que las diferencian netamente, como así también de las asociaciones, que son la otra vertiente en la que suelen ser ubicadas, sea originalmente o por descarte ${ }^{43}$.

En suma, las cooperativas tienen notas claramente diferentes de las sociedades y las asociaciones, sin perjuicio de lo cual han sido incluidas durante mucho tiempo

que una cooperativa, igual que cualquier sociedad lucrativa, obtenga beneficios sociales de la intermediación, (...) La diferencia debe residir en la forma de distribución (...): en el caso de las sociedades lucrativas, la distribución a los socios se realizará en función del capital aportado y en el caso de las cooperativas, después de atender los fondos obligatorios (incluido el FEP), la adjudicación a sus miembros se realizará en proporción a las operaciones, servicios o actividades realizadas por cada uno en la entidad." (vid. GADEA SOLER, E.: "Un análisis jurídico en torno a la identidad de una sociedad cooperativa en un sistema de economía de mercado". En: Derecho Cooperativo e Identidad Cooperativa (orgs. DE MIRANDA, J.E., DE SOUZA, L.R. \& GADEA SOLER, E.), Brazil Publishing, Curitiba, 2019, p. 103).

42. Preguntándose para qué una teoría del derecho cooperativo, Hagen Henrÿ responde que "Como fundamentación y marco de referencia para la práctica una teoría no solo facilita entender esa práctica, sino permite también formular enunciados generales útiles, por ejemplo, para llenar lagunas y evaluar las consecuencias jurídicas y extrajurídicas de la práctica, así como predecir (y, por ende, controlar) posibles consecuencias de un cambio de ésa." (vid. HENRŸ, H.: "Una teoría del derecho cooperativo. ¿Para qué?”. En: Derecho Cooperativo e Identidad Cooperativa (orgs. DE MIRANDA, J.E., DE SOUZA, L.R. \& GADEA SOLER, E.), Brazil Publishing, Curitiba, 2019, p. 177).

43. Antonio Fici sostiene: "Cooperatives, in fact, should be understood and studied, particularly by legal scholars, simply as one of the possible legal types of private organizations provided by the legislatures." (vid. FICI, A.: "An Introduction to Cooperative Law". En: International Handbook of Cooperative Law (eds. CRACOGNA, D., FICI, A. \& HENRŸ, H.), Springer, Heidelberg, 2013, p. 6). 
entre ellas negándose de esa manera su peculiar naturaleza, pero la legislación ha ido progresivamente incorporando sus notas diferenciales y, en fin, llegado a reconocer su tipicidad. Especialmente, ha llegado a reconocer que el vínculo con sus asociados difiere del que las sociedades en general establecen con sus clientes puesto que dicho vínculo es de carácter asociativo y no contractual ${ }^{44}$, manifestándose a través de una relación singular consistente en la prestación de un servicio exenta de finalidad lucrativa. Se trata de un vínculo que materializa una triple calidad de los asociados: son, a la vez, los dueños o propietarios de la entidad, los destinatarios del servicio que constituye su objeto social y quienes la gestionan. Esa triple condición no tiene lugar en las sociedades ni en las asociaciones. De allí su carácter diferente que reclama un tratamiento jurídico adecuado y singular; no es otro que el que se surge de su propia naturaleza y se manifiesta en sus estatutos y en la legislación específica. Esa es la razón de ser del derecho cooperativo. Esta singularidad se manifiesta en el acto cooperativo o la actividad cooperativizada ${ }^{45}$. Sin embargo, sucede que, aun reconociendo la peculiaridad de la relación que se establece entre el asociado y la cooperativa para la prestación del servicio que constituye el objeto ésta, existe resistencia a avanzar para fundar en esa singularidad una nueva rama jurídica que la tematice como objeto propio. Pero debemos entender que se trata solamente de una etapa hacia ulteriores desarrollos.

La cuestión medular parece estar centrada en la compleja naturaleza de la cooperativa como dato prejurídico. En efecto, si nos atenemos a la definición que de ella

44. Antonio Fici apunta: "This particular activity with the members -which may be termed "cooperative enterprise"- is a characteristic of cooperatives that, when properly understood, significantly contributes to their distinction from companies." Y cita a Margaret Digby: "there is ... something more precise which distinguishes co-operative from other business activities, something which belongs partly to end and partly to means." (FICI, A.: "An introduction...", p. 23 y nota 76. Ver también p. 30 y nota 97). Tullio Ascarelli señala que la sociedad corriente desarrolla su actividad con los terceros, en tanto que la cooperativa lo hace con sus socios, por lo que la ventaja es adquirida directamente por éstos (vid. ASCARELLI, T.: "Cooperativa e Societá”, Rivista delle Societá, 1957, p. 307, ap. PASTORINO, R.J.: Teoría general del acto cooperativo, Intercoop Editora Cooperativa, Buenos Aires, 1993, p. 25). Ver también: MÜNKNER, H.H.: "Germany". En: International Handbook of Cooperative Law (eds. CRACOGNA, D., FICI, A. \& HENRŸ, H.), Springer, Heidelberg, 2013, p. 416.

45. Véase el interesante desarrollo que realiza Vargas Vasserot al respecto en su ponencia presentada en el Congreso Continental de Derecho Cooperativo que tuvo lugar en San José de Costa Rica en 2019. Sostiene que, si bien es dable afirmar la existencia del acto cooperativo, la actividad cooperativizada como expresión singular de la cooperativa, ello no conduce necesariamente a afirmar la existencia de un Derecho Cooperativo como rama autónoma y que, en todo caso, la regulación jurídica de la cooperativa forma parte del Derecho Comercial. Señala que es generalizado, al menos en Espańa, el reconocimiento de la cooperativa como sociedad comercial, a pesar de sentencia del Tribunal Constitucional que dio lugar a asignar competencia a las comunidades autónomas para legislar en esta materia por estimar, precisamente, que las cooperativas no tienen naturaleza comercial (vid. VARGAS VASSEROT, C., op. cit., 2020, p. 36). 
brinda la Declaración sobre la Identidad Cooperativa, se trata de "una asociación autónoma de personas que se unen voluntariamente para satisfacer sus necesidades y aspiraciones económicas, sociales y culturales comunes mediante una empresa de propiedad conjunta democráticamente controlada." 46 (Destacado añadido).

La coexistencia dentro de una misma entidad de una asociación y una empresa da pábulo para diferentes maneras de considerar a la cooperativa ofreciendo fundamento para su ubicación en el seno de diversas ramas del derecho ${ }^{47}$. Básicamente, el derecho civil si se hace prevalecer el carácter de asociación y el derecho comercial si se la enfoca como empresa ${ }^{48}$. Esta tensión, que se manifiesta tanto en la teoría como en la práctica de las cooperativas, condujo a distintas posiciones que finalmente exacerban los perfiles de uno u otro carácter para dar mayor asidero a cada una de ellas pero, a la postre, resultan siempre parciales e insuficientes.

Cada una de tales posiciones implica retacear alguna porción de la naturaleza de la cooperativa e inevitablemente conduce a excesos que la desfiguran puesto que al ubicarla en una determinada placenta necesariamente se la alimenta de los rasgos y características propios de ella y se la identifica progresivamente con sus institutos típicos con lo cual la cooperativa va perdiendo inevitablemente su singularidad. Tales excesos conducen inexorablemente a las deformaciones que se conocen como "economicismo" y "socialismo" ${ }^{49}$ en la concepción de las cooperativas.

De allí que una exigencia conceptual ineludible conduzca a reconocer que la cooperativa para ser fiel a su naturaleza -o a su identidad, como actualmente se re-

46. Es interesante destacar que la ACI por primera vez incorpora la definición de cooperativa ubicándola como encabezamiento de la Declaración sobre la Identidad Cooperativa en forma previa a la enunciación de los valores y los principios. Las anteriores declaraciones -emanadas de los Congresos de 1937 y 1966- no contenían definición de la cooperativa; ésta surgía, en todo caso, de los principios cooperativos. Ahora la definición constituye el frontispicio de la Declaración.

47. La cuestión que se plantea supera la concepción de la cooperativa como una forma de organización susceptible de encuadrar dentro de un amplio derecho organizacional capaz de dar cuenta de la variedad de formas existentes ( $c f r$. HANSMANN, H. \& KRAAKMAN, R.: "The essential role of organizacional law", Yale Law Journal, $\mathrm{n}^{\circ}$ 110(3), 2000, pp. 387 y ss).

48. Véase el análisis que realiza Francesco Galgano, acerca de la incorporación de las cooperativas en el Código Civil italiano de 1942 y sus consecuencias (vid. GALGANO, F.: Instituciones de la economía capitalista, Editorial Ariel, Barcelona, 1990, p. 213).

49. El término "socialismo" está utilizado no en el sentido político sino como referencia a la prevalencia del carácter social de las cooperativas frente a la tesis que privilegia su carácter económico. Sin embargo, es perceptible también una cierta connotación vinculada a las ideas del socialismo utópico. Aitor Bengoetxea Indica tres concepciones acerca de las cooperativas: asociación, sociedad sui generis y sociedad mercantil (vid. BENGOETXEA ALKORTA, A.: "Las cooperativas", CIRIEC-España, Revista Jurídica de Economía Social y Cooperativa, no 29, 2016, pp. 205 y ss). 
clama $^{50}$ - debe zafar de anclarse en forma exclusiva en alguna de esas posturas y ello implica admitir que no es una asociación ni una empresa sino una armónica fusión de ambas que resulta en una entidad singular. Obviamente, esta circunstancia viene a complicar la comodidad que entrańa alojar a la cooperativa en el seno de una de las tradicionales ramas del derecho ya consolidadas y con un repertorio de institutos y herramientas teóricas ampliamente conocidos que facilitan operar con ellos en la consideración y solución de los problemas que aquélla plantea. Empero, esta solución, aunque sin duda más confortable, no permite dar cuenta de la singular naturaleza cooperativa pues no reconoce su identidad. La mayor dificultad que ese reconocimiento plantea es el precio que debe tributarse para posibilitar el progreso del derecho mediante la incorporación de una realidad social diferente que demanda un tratamiento apropiado.

El camino más transitado suele consistir en la asimilación de la cooperativa al repertorio de las sociedades comerciales, con lo cual ella deviene tan solo una forma jurídica más dentro del repertorio de aquéllas, sin ninguna diferencia sustancial ${ }^{51}$. Esta concepción es la que se denomina "companización", a la que Henrÿ señala como una seria amenaza para las cooperativas ${ }^{52}$.

Por otro lado, durante mucho tiempo se ha ido produciendo una corriente que si bien entraña un reconocimiento al potencial intrínseco de las cooperativas para impulsar el desarrollo económico y social, se convirtió en un lastre que perjudicó su carácter autónomo e independiente. Se trata de la consideración de las cooperativas como "instrumentos de desarrollo". La sola expresión conlleva una nota peyorativa en cuanto afirma el carácter meramente instrumental de las cooperativas al servicio de otros objetivos; es decir que reduce a la cooperativa al papel de una mera

50. El XXXIII Congreso de la ACI que se realizará en Seúl en diciembre de 2021 en conmemoración de los 125 años de esa organización y de los 25 de la Declaración sobre la Identidad Cooperativa, tiene como lema "Profundicemos nuestra identidad cooperativa" y en preparación de dicho encuentro se vienen realizando reuniones, seminarios y publicaciones en distintas partes del mundo para reflexionar sobre el tema, incluso desde el punto de vista jurídico.

51. Galgano, con particular agudeza, puntualiza que frente al desafío que las cooperativas representan para la economía capitalista, las legislaciones en lugar de perseguirlas han optado por el camino de sabotearlas mediante su asimilación a las sociedades de capital como manera más efectiva y menos evidente de oponerse a su desarrollo (vid. GALGANO, F., op. cit., p. 207).

52. Henrÿ utiliza esta expresión en Guidelines for Cooperative Legislation (p. 5). Asimismo, señala el imperativo de que la legislación refleje el carácter distintivo de la cooperativa (vid. Ibid.: "Retos y oportunidades de la globalización para las cooperativas y el marco legal cooperativo", CIRIEC-España, Revista Jurídica de Economía Social y Cooperativa, no 18, 2007, pp. 13-16). Interesantes reflexiones sobre esta cuestión formula: VICENT CHULIÁ, F.: "El futuro de la legislación cooperativa", CIRIEC-España, Revista Jurídica de Economía Social y Cooperativa, no 13,2002 , pp. 1 y ss. 
herramienta aun cuando, efectivamente, la cooperativa es naturalmente impulsora del desarrollo en virtud de sus características intrínsecas y de los principios que la informan. Pero la gravedad del asunto excede esa connotación puesto que -debido a la consideración frecuente del Estado como el primer responsable del desarrollo económico y social- las cooperativas pasarían, por carácter transitivo, a convertirse en instrumentos del Estado. Y no ya del Estado en sentido general y abstracto, sino de los gobiernos como su expresión real y concreta. Las lamentables consecuencias de esta concepción resultan de toda evidencia.

Aun dejando de lado el caso de los países comunistas en los que las cooperativas pasaron a ser tratadas como parte de la planificación estatal perdiendo de esa manera todo respeto de su autonomía e independencia, esta concepción reviste una especial gravedad en el caso de los países llamados en desarrollo en los que se le asigna un carácter complementario y subordinado de la acción estatal ${ }^{53}$. De tal suerte las cooperativas pasan a ser consideradas como una parte -o apéndice- del aparato burocrático gubernamental. En tales circunstancias, la legislación sobre cooperativas pasa a formar parte del derecho administrativo perdiendo, obviamente, toda posibilidad de llegar a configurar una rama autónoma. Pero con una singular agravante: ya no son parte del derecho privado sino que pasan a integrar el derecho público del Estado, lo cual es de especial trascendencia puesto que de esa forma vienen a integrar el aparato gubernamental, ajeno a la libre voluntad privada de quienes forman parte de las cooperativas $^{54}$.

\section{El objeto propio}

Frente a la compleja situación descripta no parece que exista otra forma de superación que no sea identificar y aislar un objeto propio que sirva de fundamento para la existencia de un Derecho Cooperativo con sustentable pretensión de autonomía. Un objeto propio que no quede atrapado en las redes teóricas de las otras ramas sino

53. Cabe señalar que son frecuentes los casos en que los organismos internacionales han incurrido en excesos acerca del papel de las cooperativas en el desarrollo y abierto así camino a que los gobiernos las consideraran como parte de su engranaje administrativo. En ese terreno, la legislación cooperativa ha sido vista como un instrumento para el logro de objetivos, generalmente plausibles, de desarrollo económico y social. (vid. SHAH, A.: "Cooperative law: An instrument for development?", International Labour Review, no 131(4-5), Ginebra, 1992, pp. 513 y ss).

54. El profesor Hans-H. Münkner, ha estudiado con especial dedicación y profundidad la situación de las cooperativas -y de la legislación cooperativa- en los países en desarrollo de Asia y Africa y ha formulado enseñanzas particularmente valiosas al respecto (vid. MÜNKNER, H.H.: Cooperative Law as an Instrument of State Sponsorship of Co-operative Societies, Organización Internacional del Trabajo (OIT), Ginebra, pp. 27-42). 
que las rebase por no ser susceptible de aprehensión satisfactoria por ellas puesto que tiene caracteres singulares que escapan de su escenario ${ }^{55}$.

Tradicionalmente se ha sostenido que existen tres requisitos para la constitución de una rama autónoma del derecho, a saber: autonomía legislativa, autonomía didáctica y autonomía científica ${ }^{56}$. Sin mayor hesitación puede afirmarse que existe autonomía legislativa en materia cooperativa puesto que, al menos desde comienzos del Siglo XX, la legislación cooperativa ha cobrado expansión habiéndose consolidado en numerosos países; y sigue creciendo. En cuanto a la autonomía didáctica, si bien la cuestión no es tan categórica como en el caso de la legislación, puede afirmarse que ha logrado un cierto grado de desarrollo en diferentes países en los que existen cursos universitarios o asignaturas independientes sobre la materia, llegando en ciertos casos a constituir una especialización ${ }^{57}$. Sobre lo que aún no existe consenso es en punto a la autonomía científica que es, precisamente, el nudo gordiano de la cuestión. En efecto, numerosos autores llegan a admitir la autonomía en las anteriores esferas, pero no en el campo científico. Y es allí donde corresponde avanzar.

Para poder pisar terreno firme es necesario acudir al estudio de la realidad cooperativa, pues en la experiencia se halla el fundamento de la ciencia y no en la pura especulación teórica ${ }^{58}$. La atenta y desprejuiciada observación de esa realidad permite apreciar que en ella existen elementos singulares, tanto subjetivos como objetivos y finalistas. Allí están la cooperativa y sus asociados, protagonistas de la relación jurídica que tiene por objeto realizar el objeto social de la cooperativa (suministro de artículos de consumo; comercialización e industrialización de productos agrarios; provisión de trabajo; abastecimiento de insumos; dotación de vivienda; etc.) cumpliendo con una finalidad de servicio no lucrativa. Estos elementos se hallan

55. A pesar de reconocer las peculiaridades de las cooperativas, Antonio Fici sostiene que "El derecho cooperativo pertenece al derecho de sociedades, compartiendo así, en principio, sus objetivos generales" (vid. FICI, A.: "El papel esencial del derecho cooperativo", CIRIEC-España, Revista Jurídica de Economía Social y Cooperativa, $\mathrm{n}^{\circ} 27,2015$, p. 17).

56. Waldirio Bulgarelli ha buceado en este tema con particular idoneidad y concluye en la innegable posibilidad de la autonomía del Derecho Cooperativo (vid. BULGARELLI, W.: Elaboraçao do Direito Cooperativo, Atlas, São Paulo, 1967, p. 15).

57. Acerca del desarrollo histórico de la relación entre la universidad y el cooperativismo, vid. CRACOGNA, D.: "Cooperativismo y Universidad: pasado y presente", Boletin de la Asociación Internacional de Derecho Cooperativo (BAIDC), no 42, 2008, pp. 59 y ss. En el mismo número están incluidos varios interesantes artículos sobre el mismo tema.

58. Es verdad que las distintas escuelas del pensamiento jurídico tienen diferentes posiciones a este respecto, pero no cabe duda de que el derecho no es un objeto que sea ajeno a la realidad puesto que versa sobre la regulación de conductas, aspecto que tiene fuerte asidero en la realidad. Si la ciencia jurídica sólo enfoca el estudio de las normas o de los valores -como la justicia- estará marginando el núcleo central de su finalidad. 
presentes en toda clase de cooperativas, cualquiera que sea su actividad específica, es decir son suficientes, y si falta alguno de ellos no se configura la realidad cooperativa, puesto que son también necesarios. Allí radica el acto cooperativo como núcleo significativo esencial ${ }^{59}$. Si esa es la realidad cooperativa, ello significa que ha menester de un ámbito científico jurídico que de cabalmente cuenta de ella, sin acudir a refugiarse en construcciones teóricas diseñadas para objetos de diferente naturaleza. Esa exigencia propia de objetos distintos dio lugar al nacimiento de diferentes disciplinas jurídicas que, partiendo de su reconocimiento, fueron progresivamente elaborando su arsenal teórico distintivo ${ }^{60}$. De esa manera progresa el conocimiento jurídico, sin aferrarse a esquemas teóricos que la realidad supera sino procurando darle a nuevos objetos un tratamiento adecuado a su singularidad. Así se satisface la necesidad teórica de parcelar el conocimiento jurídico conforme con los objetos que habitan dentro de él adjudicando a cada ciencia particular de la Dogmática el estudio de un objeto propio pues de otra suerte se destruye la unidad de la ciencia como consecuencia de la apropiación de múltiples objetos diversos ${ }^{61}$. Por supuesto, ello sólo constituye el primer -aunque decisivo- paso en la construcción de una rama autónoma del derecho

59. Sobre el tema del acto cooperativo existe una bibliografía importante que comenzó antes de que el legislador se apercibiera de él, como producto de la observación que los estudiosos hicieron de la realidad cooperativa. Se puede ubicar ese reconocimiento de la doctrina en los mediados del Siglo XX y a partir de entonces fue cobrando significativo impulso para llegar a la legislación y la jurisprudencia. Entre las obras de doctrina merecen destacarse: BULGARELLI, W.: op. cit.; CORBELLA, C.J.: Los actos cooperativos, Intercoop Editora Cooperativa, Buenos Aires, 1985; TORRES Y TORRES LARA, C.: Derecho Cooperativo. La teoría del acto cooperativo, Instituto de Estudios Latinoamericanos (INESLA), Lima, 1990; ESTELLER ORTEGA, D.: El acto cooperativo, Universidad Central de Venezuela (UCV), Caracas, 1986; y PASTORINO, R.J.: op. cit.; como así también las ponencias presentadas en los Congresos Continentales de Derecho Cooperativo realizados en distintos países de América Latina a partir de 1969. Para una visión introductoria, vid. CRACOGNA, D.: Estudios de Derecho Cooperativo, Intercoop Editora Cooperativa, Buenos Aires, 1986, pp. 13 y ss. Cabe puntualizar que existe controversia doctrinaria acerca de los alcances del acto cooperativo puesto que hay autores que consideran que éste no solamente es el que realiza la cooperativa con sus asociados (acto interno o directo) sino también el que la cooperativa realiza como condición para poder realizar el acto interno, como sucede cuando la cooperativa de consumo se aprovisiona de la mercadería (acto externo o indirecto) que luego distribuirá entre sus asociados o cuando la cooperativa agrícola comercializa con terceros la producción que ha acopiado de sus asociados. (Ver al respecto: DE CONTO, M.: "Ato Cooperativo". En: Sociedades cooperativas (coord. NETO, A.A.G.), Lex Editora, São Paulo, 2018, pp. 185-189; y LOPES BECHO, R.: Elementos de Direito Cooperativo, Dialética Ediciones, São Paulo, 2002, pp. 148 y ss).

60. Así, el acto de comercio -caracterizado por las nociones intermediación y lucro- dio lugar en su momento a la construcción teórica propia del Derecho Comercial y de igual manera sucedió con el acto administrativo, el acto civil, etc.

61. Refiriéndose al tema, afirma Jorge Joaquín Llambías que el acto jurídico "es el medio por el cual el hombre impone un orden de relaciones jurídicas adecuado a las diversas finalidades que se propone alcanzar." (vid. LLAMBÍAS, J.J.: Tratado de Derecho Civil. Parte General, T. II, AbeledoPerrot, Buenos Aires, 1997, p. 279). 
puesto que a partir de allí sobreviene la ingente tarea de impulsar su desarrollo, la cual constituye un afán permanente ${ }^{62}$.

Sin embargo, es constante el acoso que se cierne sobre los incipientes intentos de personalización del Derecho Cooperativo, tanto por parte de las ramas tradicionales del derecho como también por las nuevas que van surgiendo y le disputan su pretensión de autonomía. Caso evidente constituye el Derecho del Trabajo que pretende negar la naturaleza propia del vínculo existente entre la cooperativa de trabajo y sus asociados, reduciéndolo a un mero contrato de trabajo, subsumiendo de esa manera a la cooperativa en el ámbito laboral. No menos representativo es el caso del llamado Derecho del Consumidor que niega la particular naturaleza del vínculo que se establece entre la cooperativa de consumo y sus asociados, sosteniendo que no es otra cosas que una relación entre proveedor y cliente ${ }^{63}$. El Derecho de la Competencia tempranamente intentó afirmar que las cooperativas agrarias formadas por agricultores para comercializar conjuntamente sus productos constituían una organización cartelizada para infringir las reglas del mercado mediante prácticas monopólicas ${ }^{64}$. Las cooperativas que actúan en el terreno de los servicios esenciales (provisión de electricidad, de agua, de gas, de telefonía, etc.) permanentemente deben afrontar los embates provenientes del Derecho Administrativo que reivindica en forma exclusiva la regulación de estos servicios afirmando su carácter de servicios públicos y, consiguientemente, excluyendo las normas específicamente cooperativas aun cuando las cooperativas que los prestan están formadas sobre la base de la decisión libre y voluntaria de sus propios asociados usuarios de tales servicios ${ }^{65}$.

62. Henrÿ reclama: "Tenemos que elaborar una teoría del derecho cooperativo con el fin de establecer la autonomía de la disciplina del derecho cooperativo." (vid. HENRŸ, H.: "Reflexiones en torno al derecho cooperativo desde una perspectiva global”, Congreso Continental de Derecho Cooperativo. San José, 18-20 de noviembre de 2019, Cooperativas de las Américas, San José, 2020, p. 119).

63. Vid. CRACOGNA, D.: El acto cooperativo y la defensa del consumidor, Gabinete Universitario de Investigación, Docencia y Extensión sobre Cooperativas y otras entidades de economía social, Bahía Blanca, 2013, pp. 333 y ss.

64. Es ilustrativo el proceso vivido por las cooperativas agrarias de los EEUU que debieron soportar un duro ataque que amenazaba su propia existencia hasta que, finalmente, la Capper - Volstead Act de 1922 les reconoció su papel y pudieron superar el trance (vid. Roy, E.P.: Cooperativas: Hoy y Mañana, Editorial Albatros, Buenos Aires, 1969, pp. 212-213).

65. Vid. CRACOGNA, D.: "Naturaleza y régimen jurídico de las cooperativas de servicios públicos". En: Cooperativas de servicios públicos (auts. BALESTRA, R.H., CARELLO, L.A., CASSAGNE, J.C., CRACOGNA, D., DROMI, J.R., HALPERÍN, D.A. \& HUTCHINSON, T.), Intercoop Editora Cooperativa, Buenos Aires, 1987, p. 43 y ss. Con mayor amplitud, vid. FERNÁNDEZ DE ANDREANI, P.: Cooperativas prestadoras de servicios públicos, Editorial Astrea, Buenos Aires, 2017. 
En suma, el Derecho Cooperativo se encuentra sometido a múltiples y diversos acosos provenientes tanto de ramas del derecho preexistentes que no consienten el surgimiento de una nueva competidora en el ámbito que consideran privativo de ellas, como así también de otras nuevas que van apareciendo y que para afirmar su vigencia pretenden disputarle un terreno en el que ellas aspiran a consolidarse.

\section{Aproximaciones que amenazan la singularidad del Derecho Cooperativo}

Dejando de lado la competencia que el Derecho Cooperativo debe afrontar por parte de distintas ramas del derecho en forma más o menos abierta, existe una solapada búsqueda de su captación por parte de otras que aspiran a subsumirla dentro de ellas en virtud de su afinidad, sea ésta real o pretendida. Se trata de una manera más sutil de procurar su anulación por subsunción dentro de un marco más abarcativo.

Esta tendencia se ha visto desarrollada en años relativamente recientes, a diferencia de lo sucedido con los casos anteriormente considerados. Incluso sucede con novedosas corrientes jurídicas surgidas a partir del propio Derecho Cooperativo. Hay dos casos arquetípicos. Uno de ellos se orienta a significar que dentro del derecho societario existen manifestaciones que cumplen -o suplen- las funciones propias de las cooperativas con la ventaja de que a la vez mantienen los atributos que caracterizan a las sociedades de capital. Es la corriente de la Responsabilidad Social Empresaria $(\mathrm{RSE})^{66}$ que se ha difundido en forma notable en numerosos países proclamando que las empresas lucrativas pueden realizar finalidades sociales sin por ello dejar de perseguir ganancias como su fin principal. Incluso se abre paso el surgimiento de una variante empresaria que materializa específicamente esa orientación: las sociedades $B$ o benefit societies que, con perfiles más o menos similares han llegado a ser materia de una regulación legal especial en diferentes países ${ }^{67}$.

La otra corriente, mucho más cercana al Derecho Cooperativo, que busca involucrar a éste dentro de su territorio, es el llamado Derecho de la Economía Social. Su

66. La RSE o Corporate Social Responsability (CRS) ha cobrado ímpetu en época reciente. Gadea Soler afirma que "la existencia de paralelismos entre la filosofía que promueve la RSE y la identidad cooperativa es algo evidente" (vid. GADEA SOLER, E., op. cit., p. 113).

67. Sobre las empresas B se ha producido abundante bibliografía en época reciente y se han formado entidades que propician su difusión. Una aproximación al tema puede consultarse en: CRACOGNA, D.: "Transformaciones en el derecho societario. Las sociedades de beneficio e interés colectivo". En: Estudios de Derecho Comercial. Homenaje al Prof. Dr. José A. Ferro Astray (dir. OLIVERA GARCÍA, R.), T. I, La Ley Uruguay, Montevideo, 2020, pp. 191 y ss. 
tesis central consiste en afirmar que las cooperativas son expresiones de una especie dentro del género de las organizaciones de la economía social que comprende a varias otras entidades, tales como las mutuales, las asociaciones, las fundaciones y otras más según el repertorio de formas jurídicas existentes en cada ordenamiento jurídico nacional. Vale decir que no se desconoce a las cooperativas, pero se las relega a la consideración de una mera clase de entidades pertenecientes a un género común. Aún más, suele concederse que las cooperativas constituyen la categoría más importante del género $y$, en tal sentido, se admite que sus principios se expanden y proyectan hacia todas o la mayoría de las demás, pero siempre como parte de un conjunto más o menos homogéneo de organizaciones afines. Ese conjunto permanece indefinido en cuanto a sus alcances pues se trata de un todo abierto a nuevas incorporaciones, lo cual resulta todavía más ambiguo e impreciso cuando a la denominación Derecho de la Economía Social se le agrega "y Solidaria” o aún "Solidaria y Popular", con lo cual sus fronteras devienen permanentemente móviles y difusas. Curiosamente este avance va conquistando una cantidad creciente de adeptos en los ámbitos académicos, gubernamentales, de las organizaciones sociales y de los organismos internacionales. Consiguientemente, el Derecho Cooperativo se va diluyendo, en muchos casos con la complacencia de sus propios cultores que consideran que de esa manera ensanchan sus horizontes.

\section{La geografía del Derecho Cooperativo}

Para cerrar el desarrollo del tema es del caso efectuar una mirada de orden territorial al Derecho Cooperativo, toda vez que el análisis científico de la cuestión siempre se halla sujeto a algún tipo de dimensión geográfica, no porque la ciencia tenga necesariamente una frontera espacial sino porque su asidero y desarrollo suelen afincarse en un lugar determinado. Obviamente, ello no obsta, como se verá, al posterior ensanchamiento de su horizonte teórico.

Históricamente ha ocurrido que el derecho positivo -todo derecho positivo- se desarrolla a partir de las normas que rigen la convivencia de una comunidad determinada, cualquiera sea el ámbito geográfico sobre la que ésta se asiente. En los tiempos modernos, con el surgimiento y consolidación de los estados nacionales, son éstos los que constituyen el espacio donde el derecho existe ${ }^{68}$; de allí que se hable del derecho francés o español o brasileño, etc. A su vez, dentro de cada uno de ellos, se ubican 
los derechos en particular o ramas del derecho. En este último casillero se localiza el Derecho Cooperativo.

Sin embargo, existen casos en los que, por la organización político constitucional de algunos países, el Derecho Cooperativo suele desarrollarse en espacios territoriales que no coinciden con el ámbito nacional. Así ocurre en naciones cuya organización política adjudica competencias legislativas, además de administrativas y judiciales, a unidades territoriales de menor dimensión ${ }^{69}$.

Lo dicho sucede especialmente en los países de estructura federal o confederal, en los cuales los diferentes estados o provincias que los integran cuentan con competencia para legislar en materia de cooperativas y, correlativamente, con atribuciones administrativas y judiciales para entender en ella ${ }^{70}$. Ejemplos ilustrativos son los Estados Unidos de América, Canadá, India y Australia, entre otros. Y también España, donde las comunidades autónomas tienen reconocida competencia en distintas materias en virtud de la Constitución del Estado de 1978 y de la jurisprudencia del Tribunal Constitucional en materia de cooperativas ${ }^{71}$. En tales países sucede que cada unidad político-administrativa legisla sobre la materia de manera autónoma, con lo cual dentro de un mismo país coexisten diversas leyes con obvias diferencias -más o menos importantes- entre sí. Por lo tanto, el Derecho Cooperativo se manifiesta en un nivel infra nacional.

Adicionalmente suele suceder que en esos países existen también leyes nacionales sobre cooperativas juntamente con las leyes regionales, estatales o provinciales. Estas leyes nacionales pueden ser generales, es decir que rigen a toda clase de cooperativas, o bien especiales, referidas a determinadas clases de cooperativas, como las financieras. Si se trata de leyes generales suelen aplicarse a cooperativas con actuación en más de un estado, región o provincia, o bien aplicarse supletoriamente cuando determinado aspecto no tiene regulación local; o, incluso, aplicarse en ambos supuestos. Si se trata de leyes especiales que versan sobre cuestiones que competen al orden nacional o federal, su aplicación desplaza a las leyes locales.

69. Esta cuestión ha sido, y continúa siendo, materia de arduo debate político en cuanto a los alcances de las competencias legislativas y jurisdiccionales de las diferentes unidades políticas dentro de cada nación; y aún más allá de ellas, como sucede en los países del Commonwealth y en los. espacios de organización supranacional producto de los procesos de integración que comienzan siendo generalmente económicos y paulatinamente van asumiendo otros ámbitos.

70. Un análisis actual de las ventajas y problemas de la organización federal del Estado puede consultarse en: HAlBERSTAM, D.: "Federalism: Theory, Policy, Law". En: The Oxford Handbook of Comparative Constitutional Law (eds. ROSENFELD, M. \& SAJÓ, A.), Oxford University Press, Oxford, 2012, pp. 576 y ss.

71. Ver al respecto: VICENT CHULIÁ, F., op. cit., pp. 19 y ss. 
De lo apuntado se desprende la complejidad existente en los casos de países con diversos niveles de legislación cooperativa, pero ello es consecuencia de su estructura político constitucional por lo que la única forma de superar las diferencias de fondo que eventualmente pudieran existir consistiría en recurrir a los principios cooperativos como orientadores de las distintas legislaciones de tal suerte de homogeneizar sus contenidos fundamentales. En suma, en estos casos el Derecho Cooperativo tendrá un ámbito geográfico circunscripto a cada una de las jurisdicciones locales respectivas.

Por otro lado se va abriendo camino una corriente orientada a la armonización del Derecho Cooperativo a nivel internacional, con distintos grados de intensidad que van desde la simple búsqueda de bases comunes en los principales institutos ${ }^{72}$ hasta la legislación uniforme ${ }^{73}$. Entre medio se ubican experiencias como la de la Sociedad Cooperativa Europea ${ }^{74}$ y el Estatuto de las Cooperativas del Mercosur ${ }^{75}$. Cabe distinguir que la armonización supone el reconocimiento de las diferentes legislaciones a las que se trata de aproximar mediante diferentes mecanismos, en tanto que la uniformización entraña la existencia de un derecho común o único para todas las naciones que en las que rige la ley uniforme ${ }^{76}$.

72. Es el caso de la Ley Marco para la Cooperativas de América Latina elaborada por un grupo de expertos por encargo de la Organización de las Cooperativas de América (OCA) en 1988. Veinte años más tarde este documento fue actualizado por la ACI Américas (hoy Cooperativas de las Américas) y posteriormente obtuvo la aprobación del Parlamento Latinoamericano, organismo formado por representantes de los parlamentos de la región que, si bien no tiene facultades legislativas, emite recomendaciones dirigidas a los parlamentos nacionales. Vid. CRACOGNA, D.: "The Framework Law for the Cooperatives in Latin America". En: International Handbook of Cooperative Law (eds. CRACOGNA, D., FICI, A. \& HENRŸ, H.), Springer, Heidelberg, 2013, pp. 165 y ss.

73. Así sucede en OHADA (Organización para la Armonización del Derecho Económico) que fue creada en 1993 y agrupa actualmente a 17 estados de Africa Central y Occidental. Esta organización elaboró una "Ley uniforme relativa al derecho de las cooperativas" que entró en vigencia en 2011 en dichos países (vid. HIEZ, D. \& TADJUDJE, W.: "The OHADA Cooperative Regulation “. En: International Handbook of Cooperative Law (eds. CRACOGNA, D., FICI, A. \& HENRŸ, H.), Springer, Heidelberg, 2013, pp. 89 y ss).

74. Existe abundante bibliografía sobre el tema, pero una visión integral se brinda en: FICI, A.: "The European Cooperative Society Regulation". En: International Handbook of Cooperative Law (eds. CRACOGNA, D., FICI, A. \& HENRŸ, H.), Springer, Heidelberg, 2013, pp. 115 y ss.

75. Vid. CRACOGNA, D.: "The Statute of Mercosur Cooperatives". En: International Handbook of Cooperative Law (eds. CRACOGNA, D., FICI, A. \& HENRŸ, H.), Springer, Heildelberg, 2013, pp. 165 y ss.

76. Las dificultades que entraña la legislación uniforme son muchas, aun cuando se trate de países con similar tradición jurídica puesto que sobre las cooperativas inciden también otras legislaciones, además de la específicamente cooperativa, y la cultura de cada país tiene también una notable influencia que se manifiesta tanto en los comportamientos individuales como en la jurisprudencia y las medidas administrativas. La experiencia de los diez años de vigencia de la Ley Uniforme de OHADA así lo demuestra. 


\section{Bibliografía}

ALIANZA COOPERATIVA INTERNACIONAL [ACI]: Compte rendu du quinzième Congrès de l'Alliance Coopérative Internationale à Paris, du 6 au 9 septembre 1937, Alianza Cooperativa Internacional (ACI), Londres, 1938.

ALIANZA COOPERATIVA INTERNACIONAL [ACI]: Twenty-Third Congress. Agenda and Reports. 5th to 8th September, 1996, Alianza Cooperativa Internacional (ACI), Bruselas, 1996.

ALIANZA COOPERATIVA INTERNACIONAL [ACI]: Guidance Notes to the Co-operative Principles, Alianza Cooperativa Internacional (ACI), Bruselas, 2015. BENGOETXEA ALKORTA, A.: "Las cooperativas", CIRIEC-España, Revista Juridica de Economia Social y Cooperativa, no 29, 2016, pp. 205-234.

BONNER, A.: British Co-operation, Co-operative Union, Manchester, 1961.

BULGARELLI, W.: Elaboração do direito cooperativo: um ensaio de autonomía, Atlas, São Paulo, 1967.

CALVERT, H.: The Law and Principles of Co-operation, Thacker, Spink \& Co., Calcutta, 1933.

CAMPBELL, W.K.H.: Practical Co-operation in Asia and Africa, W. Heffer, Cambridge, 1951.

CHÁVEZ NÚNÉEZ, F. \& ORIZET, J.: Estudio comparativo de la legislación cooperativa en América, Organización de los Estados Americanos (OEA), Washington, 1957.

CONFEDERACIÓN EUROPEA DE LA AGRICULTURA [COGECA]: Estudio comparado del derecho de la cooperación agrícola en Europa, Obra sindical "Cooperación", Madrid, 1965.

COLE, G.D.H.: A Century of Co-operation, George Allen and Unwin for The Co-operative Union, Stockport, 1944.

De CONTO, M.: "Ato Cooperativo". En: Sociedades cooperativas (coord. NETO, A.A.G.), Lex Editora, São Paulo, 2018.

CORBELLA, C.J.: Los actos cooperativos, Intercoop Editora Cooperativa, Buenos Aires, 1985.

COUTANT, L.: L'evolution du droit coopératif de ses origines â 1950, Éditions Matot-Braine, Reims, 1950.

CRACOGNA, D.: Estudios de Derecho Cooperativo, Intercoop Editora Cooperativa, Buenos Aires, 1986. 
CRACOGNA, D.: "Naturaleza y régimen jurídico de las cooperativas de servicios públicos". En: Cooperativas de servicios públicos (auts. BALESTRA, R.H., CARELLO, L.A., CASSAGNE, J.C., CRACOGNA, D., DROMI, J.R., HALPERÍN, D.A. \& HUTCHINSON, T.), Intercoop Editora Cooperativa, Buenos Aires, 1987, cap. 4.

CRACOGNA, D.: "Cooperativismo y Universidad: pasado y presente", Boletin de la Asociación Internacional de Derecho Cooperativo (BAIDC), no 42, 2008, pp. 5964. DOI: https://doi.org/10.18543/baidc-42-2008pp59-64

CRACOGNA, D. (coord.): La legislación cooperativa en México, Centroamérica y el Caribe, Alianza Cooperativa Internacional para las Américas (ACI-Américas), San José, 2009.

CRACOGNA, D. (coord.): La legislación cooperativa en los paises andinos, Alianza Cooperativa Internacional para las Américas (ACI-Américas), San José, 2009.

CRACOGNA, D. (coord.): Régimen legal de las cooperativas en los paises del Mercosur, Instituto Nacional de Asociativismo y Economía Social (INAES), Buenos Aires, 2009.

CRACOGNA, D.: "The Framework Law for the Cooperatives in Latin America”. En: International Handbook of Cooperative Law (eds. CRACOGNA, D., FICI, A. \& HENRŸ, H.), Springer, Heidelberg, 2013, pp. 165-186.

DOI: https://doi.org/10.1007/978-3-642-30129-2_6

CRACOGNA, D.: "The Statute of Mercosur Cooperatives". En: International Handbook of Cooperative Law (eds. CRACOGNA, D., FICI, A. \& HENRŸ, H.), Springer, Heidelberg, 2013, pp. 153-164.

DOI: https://doi.org/10.1007/978-3-642-30129-2_5

CRACOGNA, D.: El acto cooperativo y la defensa del consumidor, Gabinete Universitario de Investigación, Docencia y Extensión sobre Cooperativas y otras entidades de economía social (GIDECOOP), Bahía Blanca, 2013.

CRACOGNA, D.: "Transformaciones en el derecho societario. Las sociedades de beneficio e interés colectivo". En: Estudios de Derecho Comercial. Homenaje al Prof. Dr. José A. Ferro Astray (dir. OLIVERA GARCÍA, R.), T. I, La Ley Uruguay, Montevideo, 2020.

CRACOGNA, D., FICI, A. \& HENRŸ, H. (eds.): International Handbook of Cooperative Law, Springer, Heidelberg, 2013.

CUETO RÚA, J.: Fuentes del derecho, Editorial Abeledo-Perrot, Buenos Aires, 1994.

DIGBY, M.: Digest of Co-operative Law at Home and Abroad, The Horace Plunkett Foundation, Londres, 1933.

ESTELLER ORTEGA, D.: El acto cooperativo, Universidad Central de Venezuela (UCV), Caracas, 1986. 
FAJARDO GARCÍA, I.G., FICI, A., HENRŸ, H., HIEZ, D., MÜNKNER, H.H. \& SNAITH, I.: "El nuevo grupo de estudio en derecho cooperativo europeo y el proyecto "Los principios del derecho cooperativo europeo", CIRIEC-España, Revista Jurídica de Economía Social y Cooperativa, no 24, 2013, pp. 331-350.

FERNÁNDEZ DE ANDREANI, P.: Cooperativas prestadoras de servicios públicos, Editorial Astrea, Buenos Aires, 2017.

FICI, A.: "The European Cooperative Society Regulation". En: International Handbook of Cooperative Law (eds. CRACOGNA, D., FICI, A. \& HENRŸ, H.), Springer, Heidelberg, 2013, pp. 115-151.

DOI: https://doi.org/10.1007/978-3-642-30129-2_4

FICI, A.: "An introduction to Cooperative Law". En: International Handbook of Cooperative Law (eds. CRACOGNA, D., FICI, A. \& HENRŸ, H.), Springer, Heidelberg, 2013, pp. 3-62. DOI: https://doi.org/10.1007/978-3-642-30129-2_1

FICI, A.: "El papel esencial del derecho cooperativo", CIRIEC-España, Revista Juridica de Economía Social y Cooperativa, no 27, 2015, pp. 13-47.

GADEA SOLER, E.: "Un análisis jurídico en torno a la identidad de la sociedad cooperativa en un sistema de economía de mercado". En: Derecho Cooperativo e Identidad Cooperativa (orgs. De MIRANDA, J.E., De SOUZA, L.R. \& GADEA SOLER, E.), Brazil Publishing, Curitiba, 2019.

GALGANO, F.: Instituciones de la economía capitalista, Editorial Ariel, Barcelona, 1990.

HALBERSTAM, D.: "Federalism: Theory, Policy, Law". En: The Oxford Handbook of Comparative Constitutional Law (eds. ROSENFELD, M. \& SAJÓ, A.), Oxford University Press, Oxford, 2012.

DOI: https://doi.org/10.1093/oxfordhb/9780199578610.013.0029

HANSMANN, H. \& KRAAKMAN, R.: "The Essential Role of Organizational Law", Yale Law Journal, no 110(3), 2000, pp. 387-440.

DOI: https://doi.org/10.2307/797521

HENRŸ, H.: "Retos y oportunidades de la globalización para las cooperativas y el marco legal cooperativo", CIRIEC-España, Revista Jurídica de Economía Social y Cooperativa, no 18, 2007, pp. 123-138.

HENRŸ, H.: Guidelines for Cooperative Legislation, Organización Internacional del Trabajo (OIT), Ginebra, 2012.

HENRŸ, H.: "Trends and Prospects of Cooperative Law". En: International Handbook of Cooperative Law (eds. CRACOGNA, D., FICI, A. \& HENRŸ, H.), Springer, Heidelberg, 2013, pp. 803-823.

DOI: https://doi.org/10.1007/978-3-642-30129-2_38 
HENRŸ, H.: “Una teoría del derecho cooperativo. ¿Para qué?”. En: Derecho Cooperativo e Identidad Cooperativa (orgs. De MIRANDA, J.E., De SOUZA, L.R. \& GADEA SOLER, E.), Brazil Publishing, Curitiba, 2019, pp. 175-191.

HENRŸ, H.: "Reflexiones en torno al derecho cooperativo desde una perspectiva global", Congreso Continental de Derecho Cooperativo. San José, 18-20 de noviembre de 2019, Cooperativas de las Américas, San José, 2020.

HIEZ, D. \& TADJUDJE, W.: "The OHADA Cooperative Regulation “. En: International Handbook of Cooperative Law (eds. CRACOGNA, D., FICI, A. \& HENRŸ, H.), Springer, Heidelberg, 2013, pp. 89-113.

DOI: https://doi.org/10.1007/978-3-642-30129-2_3

HOLYOAKE, G.J.: Historia de los pioneros de Rochdale, Federación Argentina de Cooperativas de Consumo, Buenos Aires, 1944.

KELSEN, H.: Teoría Pura del Derecho, Universidad Nacional Autónoma de México (UNAM), México D. F., 1979.

KRYGIER, M.: "Rule of Law". En: The Oxford Handbook of Comparative Constitutional Law (eds. ROSENFELD, M. \& SAJÓ, A.), Oxford University Press, Oxford, 2012, pp. 233-234.

DOI: https://doi.org/10.1093/oxfordhb/9780199578610.013.0012

LLAMBÍAS, J.J.: Tratado de Derecho civil. Parte General, t. II, AbeledoPerrot, Buenos Aires, 1997.

LOPES BECHO, R.: Elementos de Direito Cooperativo, Dialética Ediciones, São Paulo, 2002.

MACPHERSON, I.: Co-operative Principles for the 21st Century, Alianza Cooperativa Internacional (ACI), Ginebra, 1995.

MONTOLÍO HERNÁNDEZ, J.M.: Legislación cooperative en América Latina. Situación, derecho comparado y proceso de armonización, Ministerio de Trabajo y Asuntos Sociales, Madrid, 1990.

MONTOLÍO HERNÁNDEZ, J.M.: Legislación cooperative en la Unión Europea, Ministerio de Trabajo y Asuntos Sociales, Madrid, 2001.

MÜNKNER, H.H.: Co-operative Law as an Instrument of State Sponsorship of Co-operative Societies, Organización Internacional del Trabajo (OIT), Ginebra, 1973.

MÜNKNER, H.H.: Nueva ley cooperativa de 1973 y evolución de la legislación cooperativa en la República Federal de Alemania, Organización Internacional del Trabajo (OIT), Ginebra, 1974.

MÜNKNER, H.H. (Ed.): 100 Years Co-operative Credit Societies Act India 1904, Marburg Consult for Self-help Promotion, Marburg, 2005. 
MÜNKNER, H.H.: "Germany". En: International Handbook of Cooperative Law (eds. CRACOGNA, D., FICI, A. \& HENRŸ, H.), Springer, Heidelberg, 2013, pp. 413-429. DOI: https://doi.org/10.1007/978-3-642-30129-2_18

MÜNKNER, H.H. \& ULLRICH, G. (eds.): Cooperative Law in East, Central and Southern African countries, German Foundation for International Development, Berlin, 1982.

ORGANIZACIÓN INTERNACIONAL DEL TRABAJO [OIT], R193 - Recomendación sobre promoción de las cooperativas (núm. 193), 2002.

ORGANIZACIÓN DE LAS NACIONES UNIDAS [ONU]: Cooperatives in social development [Resolución A/RES/56/114], Asamblea General de las Naciones Unidas, Nueva York, 2002.

ORGANIZACIÓN DE LAS NACIONES UNIDAS [ONU]: "Cooperatives in social development" [Resolución A/76/209], Asamblea General de las Naciones Unidas, Nueva York, 2021.

PASTORINO, R.J.: Teoría general del acto cooperativo, Intercoop Editora Cooperativa, Buenos Aires, 1993.

PETROU, T.: "Canada". En: International Handbook of Cooperative Law (eds. CRACOGNA, D., FICI, A. \& HENRŸ, H.), Springer, Heidelberg, 2013, pp. 289316. DOI: https://doi.org/10.1007/978-3-642-30129-2_12

ROY, E.P.: Cooperativas: hoy y mañana, Editorial Albatros, Buenos Aires, 1969.

SHAH, A.: "Cooperative law: An instrument for development?", International Labour Review, no 131(4-5), 1992, pp. 513-524.

SOUTHERN, R. \& ROSE, P.B.: Handbook to the Industrial and Provident Societies Act 1893-1961, Co-operative Union Ltd., Manchester, 1961.

SURRIDGE, D.J. \& DIGBY, M.: A Manual of Co-operative Law and Practice, W. Heffer, Cambridge, 1958.

TORRES Y TORRES LARA, C.: Derecho Cooperativo. La teoría del acto cooperativo, Instituto de Estudios Latinoamericanos (INESLA), Lima, 1990.

VALKO, L.: "The First Co-operative Law", Review of International Co-operation, Alianza Cooperativa Internacional (ACI), London, 1952.

VALKO, L.: International Handbook of Co-operative Legislation, State College of Washington, Pullman, 1954.

VALKO, L.: Cooperative Laws in U.S.A. Federal Legislation 1890-1980, Washington State University, College of Agriculture Research Center, Pullman, 1981.

VARGAS VASSEROT, C.: "La teoría del acto cooperativo en el derecho español". En: Congreso Continental de Derecho Cooperativo. San José de Costa Rica, 18-20 de noviembre de 2019 (comp. CRACOGNA, D.), Intercoop Editora Cooperativa, Buenos Aires, 2020, pp. 35-74. 
VICENT CHULIÁ, F.: "El futuro de la legislación cooperativa”, CIRIEC-España, Revista Juridica de Economia Social y Cooperativa, no 13, 2002, pp. 9-48.

WATKINS, W.P.: La Alianza Cooperativa Internacional 1895-1970, Intercoop Editora Cooperativa, Buenos Aires, 1973.

ZULETA PUCEIRO, E.: "La dogmática jurídica como paradigma científico", Anuario de Filosofía Jurídica y Social, no 3, 1983. 